\title{
Diversificação agrícola em localidade rural do Sul do Brasil: reflexôes e alternativas de cumprimento da Convenção-Quadro para o controle do tabaco
}

| ${ }^{1}$ Deise Lisboa Riquinho, ${ }^{2}$ Élida Azevedo Hennington |

Resumo: A diversificação agrícola em áreas de cultivo do tabaco é uma das propostas da Convenção-Quadro, considerada o primeiro tratado internacional de saúde pública da Organização Mundial da Saúde. O objetivo deste estudo é evidenciar e discutir as dificuldades e potencialidades referentes à diversificação agrícola e substituição ao cultivo do tabaco entre representantes do Estado, de organizaçōes da sociedade civil e da própria indústria, em região produtora do Sul do Brasil. Foi desenvolvido estudo do tipo etnográfico com realização de 42 entrevistas semiestruturadas, com famílias de agricultores e informantes-chave, além de observação participante das famílias, em localidade rural do estado do Rio Grande do Sul. Há políticas públicas potencializadoras da diversificação, como crédito agrícola e assistência técnica, mas elas ainda não atingiram os fumicultores pesquisados. Concluise que a ampliação e direcionamento de políticas públicas e o resgate e fortalecimento da agricultura familiar são essenciais para a diversificação agrícola e substituição do cultivo do tabaco proposta pela Convenção-Quadro.

> Palavras-chave: Saúde da população rural; tabaco; saúde pública; agricultura sustentável; pesquisa qualitativa.
1 Enfermeira; doutora em Saúde Pública pela ENSP/Fiocruz. Rio de Janeiro, Brasil. Endereço eletrônico: deise.riquinho@ gmail.com

${ }^{2}$ Médica sanitarista; doutora em Saúde Coletiva pela Unicamp; pesquisadora do Ipec e ENSP/Fiocruz. Rio de Janeiro, Brasil. Endereço eletrônico: elidahennington@gmail.com 


\section{Introdução}

A determinação social do processo saúde-doença reflete as desigualdades sociais e de saúde e, mais especificamente, as condições de vida e trabalho. As condições sociais em que as pessoas nascem, crescem, vivem, trabalham e envelhecem são os determinantes mais importantes do estado de saúde (OMS, 2011).

As características do cultivo do tabaco, pelo uso intensivo de diversos tipos de agrotóxicos aplicados em diferentes etapas, e um ciclo de trabalho árduo, do semeio à classificação das folhas, produzem efeitos danosos à saúde dos agricultores e ao ambiente. Os trabalhadores estão susceptíveis, especialmente, a lesões musculoesqueléticas, doenças respiratórias, intoxicaçōes por agrotóxicos e à doença da folha verde do tabaco (DFVT) (RIQUINHO; HENNINGTON, 2012). O ambiente é atingido pela contaminação do solo, da água e do ar. O solo é empobrecido pelo uso de agrotóxicos, aliado à monocultura do tabaco; os resíduos dos agrotóxicos atingem rios e nascentes e o ar é impregnado desses mesmos resíduos, assim como de fumaça, em época de cura (LOKER, 2005).

Alimentos consumidos pelos agricultores também são contaminados, pois apesar de os agrotóxicos não serem aplicados diretamente nos produtos que vão à mesa, são plantados ao lado das lavouras de tabaco. As consequências à saúde humana e ao ambiente, descritas pelo uso de agrotóxicos, são inerentes aos monocultivos característicos do agronegócio no Brasil, maior consumidor mundial de agrotóxicos. Além disso, do ponto de vista das relações de trabalho na cadeia produtiva do fumo, os agricultores estão submetidos a um sistema denominado de sistema integrado de produção do tabaco, com o estabelecimento de vínculo contratual com a agroindústria. Esta fica responsável por fornecer insumos e assistência técnica aos produtores, mediar a relação com os Bancos em relação a financiamentos, e adquirir toda a produção, ao final da safra.

Em 2005, o Estado brasileiro ratificou a Convenção-Quadro para o Controle do Tabaco (CQCT) - primeiro tratado mundial de Saúde Pública, que versa sobre medidas de redução no plantio e consumo de tabaco. O texto final da CQCT é constituído por 38 artigos e dois deles fazem referência direta aos trabalhadores do tabaco. No artigo 17, é recomendado que organizaçôes intergovernamentais, internacionais e regionais, em cooperação, promovam alternativas economicamente viáveis para a substituição do cultivo. No artigo 
18, as orientações dizem respeito à proteção do meio ambiente e à saúde das pessoas envolvidas com o cultivo e a fabricação de produtos do tabaco em seus respectivos territórios (OMS, 2004).

Em relação a alternativas ao cultivo do fumo, estudos realizados nos Estados Unidos evidenciaram que, dentre os agricultores que obtinham êxito na prática de diversificação agrícola ao tabaco, encontravam-se aqueles com níveis educacionais mais elevados (BEACH; JONES; TOOZE, 2008; PUSHKARSKAYA; MARSHALL, 2010). Observou-se, também, que a intenção em aderir ao programa de diversificação aumentou à medida que os incentivos ao cultivo ao tabaco diminuíram (BEACH; JONES; TOOZE, 2008). Para Pushkarskaya e Marshall (2010), a estrutura familiar também colaborou com as escolhas das formas de diversificação, investimento e despesas das famílias produtoras de tabaco. Famílias extensas investiram em empresas agrícolas, enquanto aquelas com membros idosos investiram no mercado de ações. Naquelas em que havia predominância de jovens na estrutura familiar, houve busca de trabalho não agrícola.

No Brasil, o Ministério do Desenvolvimento Agrário (MDA) lançou, no ano de 2005, o Programa Nacional de Diversificação em Áreas Cultivadas com Tabaco. No programa foram desenvolvidos 60 projetos, distribuídos em sete estados produtores de fumo (Rio Grande do Sul, Santa Catarina, Paraná, Paraíba, Sergipe, Bahia e Alagoas), atingindo aproximadamente 80 mil agricultores. Na implementação do programa, foram asseguradas parcerias entre organizações governamentais, da sociedade civil, universidades, centros de pesquisa e representações dos agricultores familiares. O programa privilegiou áreas de financiamento, acesso à tecnologia, agregação de valor à produção local e garantia de comercialização em áreas de fumicultura.

Trabalhar na perspectiva da diversificação em áreas cultivadas com tabaco requer ações para além das que estão diretamente vinculadas às questôes agrícolas, demandando ações intersetoriais que contemplem temas associados como Saúde, Educação, Meio Ambiente, Organização Social, Cultura, Lazer, Segurança Alimentar e tecnologias apropriadas (BRASIL, 2010).

No cenário da diversificação em áreas cultivadas com tabaco, além da Saúde, a Educação também se configura como preocupação governamental (BRASIL, 2010). Tanto a Educação formal, por meio dos bancos escolares, quanto à informal, na convivência com o coletivo, são estratégias de apoio aos agricultores 
na adaptação à proposta de diversificação. Apesar de o cultivo do tabaco, em algumas regiōes, fazer parte da cultura e das relações familiares, há um panorama nacional e mundial de contração no mercado consumidor, especialmente após as medidas da Convenção-Quadro, a qual tem influenciado o setor produtivo. Nessa perspectiva, observa-se a necessidade de compreender como políticas públicas e estratégias de diversificação, tais como a proposta pelo programa do MDA, em parceria com a Embrapa Clima Temperado, atingem os agricultores do tabaco. Conhecer a realidade local é uma maneira profícua de entender os desafios e as potencialidades das propostas de diversificação no microespaço de uma localidade rural com suas características, assimetrias e desigualdades.

Iniciativas de diversificação agrícola a plantadores de fumo foram documentadas por Vargas e Bonato (2007) em regiōes de concentração da produção no Rio Grande do Sul e Santa Catarina, algumas delas resgatando preceitos da Agroecologia e de conhecimentos tradicionais em respeito à saúde do trabalhador rural e ao ambiente. No entanto, ainda são medidas contrahegemônicas, com dificuldade para promover isoladamente uma transformação mais efetiva. Para isto, é necessário que políticas públicas mais amplas, movimentos sociais do campo e processos educacionais, envolvendo potenciais e atuais consumidores, fortaleçam a Agroecologia e a agricultura familiar.

$\mathrm{Na}$ realização deste estudo, teve-se por objetivo evidenciar e discutir as dificuldades e potencialidades referentes à diversificação agrícola e substituição ao cultivo do tabaco entre representantes do Estado, de organizações da sociedade civil e da própria indústria em região produtora do sul do Brasil.

\section{Percurso metodológico}

Foi desenvolvido estudo qualitativo do tipo etnográfico, em uma localidade rural produtora de tabaco no interior do Rio Grande do Sul. Segundo Geertz (2008), a descrição etnográfica é interpretativa do fluxo do discurso social, fixando o "dito" em formas pesquisáveis, numa descrição microscópica. Apesar de microscópica, essa descrição não deve perder contato com as realidades estratificadoras políticas, econômicas e de poder, dentro das quais as pessoas são condicionadas, em todos os lugares (GEERTZ, 2008; VELHO, 1978). Para isto, é preciso "mergulhar" na estrutura compreensiva e significativa da ação social, na qual a visão de mundo 
dos diferentes atores e as regras dessas interações não podem ser antecipadas.

Mesmo nas sociedades mais hierarquizadas, há momentos, situações ou papéis sociais que permitem a crítica, a relativização ou até o rompimento com a hierarquia (GEERTZ, 2008; VELHO, 1978).

O nome da localidade de estudo será mantido em sigilo, por expor práticas de trabalho por vezes em desacordo com as normas impostas pelas indústrias fumageiras que lá atuam, tais como o não uso de equipamento de proteção individual (EPI) e a presença de trabalho infantil, o que poderia gerar retaliações e prejuízos para a comunidade em questão.

Os sujeitos de pesquisa foram 23 famílias produtoras de fumo, todas ligadas direta ou indiretamente à indústria do tabaco. Buscou-se contemplar a heterogeneidade social do local: diferentes arranjos familiares e famílias que tinham entre seus membros crianças em idade escolar, diferentes etnias e distintos credos.

Entre as famílias entrevistadas, o principal arranjo foi nuclear, formado pelo casal e filhos ou por apenas a presença do casal. A maioria se identificava como "brasileiro" e a seguir como "alemão" ou "pomerano". A religião mais referida foi católica ou luterana. A idade dos agricultores entrevistados variou entre 28 a 70, anos com maior concentração etária dos 30 aos 50 anos. A média de integrantes das famílias foi de 3,4 pessoas. A maioria dos pais possuía o Ensino Fundamental incompleto e os filhos em idade escolar frequentavam a escola, exigência da indústria do tabaco. O tempo de trabalho no cultivo do fumo variou de 2 a 17 anos, com média de 7,7 anos, havendo dois casos de mais de 30 anos de cultivo.

Para melhor compreender as percepções e ações relativas à diversificação agrícola, outros atores fizeram parte do estudo: representantes do Estado, de organizações da sociedade civil e da indústria do tabaco (quadro 1), totalizando 42 entrevistas. A amostra estudada foi intencional e os entrevistados foram indicados por informantes-chave da Comunidade.

Durante as entrevistas com os agricultores, as famílias estavam reunidas, sendo possível o diálogo com todos os integrantes, mesmo os filhos menores de 18 anos. Já com os representantes do Estado, de organizaçōes da sociedade civil e indústria, as entrevistas foram agendadas e realizadas individualmente em seus locais de trabalho, exceto no Sindicato dos Trabalhadores Rurais (STR), onde a entrevista se deu com os dois entrevistados concomitantemente. 

da sociedade civil e indústria

\begin{tabular}{|c|c|c|c|}
\hline \multicolumn{4}{|c|}{ Representantes do Estado } \\
\hline Órgão & Profissão & Atividade Principal & Idade (anos) \\
\hline $\begin{array}{l}\text { Secretaria Municipal da Educação } \\
\text { (SME) }\end{array}$ & Professora & Diretora da escola local & 30 \\
\hline SME & Professora & $\begin{array}{l}\text { Orientadora educacional da } \\
\text { escola local }\end{array}$ & 28 \\
\hline $\begin{array}{l}\text { Secretaria Municipal da Agricultura } \\
\text { (SMA) }\end{array}$ & $\begin{array}{l}\text { Assistente } \\
\text { social }\end{array}$ & $\begin{array}{l}\text { Técnica agrícola, extensão } \\
\text { rural }\end{array}$ & 54 \\
\hline $\begin{array}{l}\text { Associação Riograndense de } \\
\text { Empreendimentos de Assistência } \\
\text { Técnica e Extensão Rural (Emater/RS) }\end{array}$ & $\begin{array}{l}\text { Técnico } \\
\text { agrícola }\end{array}$ & Extensionista Rural1 & 39 \\
\hline Emater/RS & Agrônomo & Extensionista Rural2 & 53 \\
\hline $\begin{array}{l}\text { Empresa Brasileira de Pesquisa } \\
\text { Agropecuária (Embrapa) }\end{array}$ & Agrônomo & $\begin{array}{l}\text { Pesquisador da agricultura } \\
\text { familiar }\end{array}$ & 52 \\
\hline \multicolumn{4}{|c|}{ Representantes de organizaçōes da Sociedade Civil } \\
\hline Órgão & Profissão & Atividade Principal & Idade (anos) \\
\hline $\begin{array}{l}\text { Movimento dos Pequenos Agricultores } \\
\text { (MPA) }\end{array}$ & Agricultor & $\begin{array}{l}\text { Fundador e ativista do } \\
\text { movimento }\end{array}$ & 36 \\
\hline Associação Comunitária Local (ACL) & Agricultor & Presidente da associação & 36 \\
\hline Líder Comunitário (LC) 1 & $\begin{array}{l}\text { Professor } \\
\text { aposentado }\end{array}$ & $\begin{array}{l}\text { Líder religioso e membro } \\
\text { da ACL }\end{array}$ & 54 \\
\hline$(\mathrm{LC}) 2$ & $\begin{array}{l}\text { Agricultor } \\
\text { Aposentado }\end{array}$ & Membro da ACL & 90 \\
\hline $\begin{array}{l}\text { Associação de Agricultores e } \\
\text { Apicultores (AAA) }\end{array}$ & Padre & Fundador e ativista da AAA & 73 \\
\hline $\begin{array}{l}\text { Associação Regional de Produtores } \\
\text { Agroecologistas da Região Sul (ARPA- } \\
\text { SUL) }\end{array}$ & Agricultor & $\begin{array}{l}\text { Membro da associação } \\
\text { ARPA-SUL }\end{array}$ & 46 \\
\hline $\begin{array}{l}\text { Sindicato dos Trabalhadores Rurais } \\
\text { (STR) } 1\end{array}$ & Agricultor & $\begin{array}{l}\text { Participante do programa de } \\
\text { crédito fundiário }\end{array}$ & 49 \\
\hline STR2 & Agricultor & $\begin{array}{l}\text { Participante do programa de } \\
\text { crédito fundiário }\end{array}$ & 59 \\
\hline $\begin{array}{l}\text { Centro de Apoio ao Pequeno Agricultor } \\
\text { (CAPA) }\end{array}$ & $\begin{array}{l}\text { Técnico em } \\
\text { enfermagem }\end{array}$ & $\begin{array}{l}\text { Educadora em saúde junto } \\
\text { aos agricultores }\end{array}$ & 46 \\
\hline $\begin{array}{l}\text { União das Associações Comunitárias } \\
\text { (UAC) }\end{array}$ & $\begin{array}{l}\text { Técnico } \\
\text { agrícola }\end{array}$ & $\begin{array}{l}\text { Apoiador da produção } \\
\text { agroecológica e do } \\
\text { cooperativismo }\end{array}$ & 31 \\
\hline
\end{tabular}




\begin{tabular}{|l|l|l|l|}
\hline \multicolumn{4}{|c|}{ Representantes da Indústria } \\
\hline Órgão & \multicolumn{1}{|c|}{ Profissão } & \multicolumn{1}{c|}{ Atividade Principal } & Idade (anos) \\
\hline Indústria do tabaco & Técnico em & $\begin{array}{l}\text { Instrutor da indústria1. } \\
\text { Responsável pela captação } \\
\text { dos agricultores no início do } \\
\text { plantio e acompanhamento } \\
\text { da atividade, como os } \\
\text { pedidos de insumos e a } \\
\text { comercialização. }\end{array}$ & 31 \\
\hline Indústria do tabaco & Técnico \\
agrícola & $\begin{array}{l}\text { Instrutor da indústria2. } \\
\text { Idem ao primeiro. }\end{array}$ & 30 \\
\hline Indústria do tabaco & $\begin{array}{l}\text { Técnico } \\
\text { agrícola }\end{array}$ & $\begin{array}{l}\text { Instrutor da indústria3. } \\
\text { Idem ao primeiro. }\end{array}$ & 30 \\
\hline
\end{tabular}

Fonte: Riquinho (2012).

A produção dos dados ocorreu em duas etapas: 42 entrevistas semiestruturadas e observação participante, com cinco das 23 famílias produtoras de fumo da localidade. A pesquisa ocorreu durante 90 dias de trabalho de campo na localidade, de dezembro a agosto de 2011. A escolha desse período oportunizou o acompanhamento de um ciclo de trabalho no cultivo do tabaco, do plantio à classificação do fumo, privilegiando a observação das etapas desse trabalho.

A fase de análise teve início a partir da produção dos dados. Estar com os participantes da pesquisa, observar seus modos de vida, bem como a relação com eles estabelecida, tudo isso repercutiu no material analisado. Segundo Geertz (2001), a análise, na pesquisa qualitativa, é uma modalidade de experiência moral, à medida que emerge de um contato direto com os detalhes do cotidiano, afetando a sensibilidade de quem a realiza. $\mathrm{O}$ tratamento do material, produzido a partir das entrevistas e da observação, ocorreu por meio de categorização temática (MINAYO, 2007). Na fase de organização e análise dos dados, o software NVivo 7.0 auxiliou na codificação e tratamento do material.

O projeto de pesquisa foi submetido e aprovado pelo Comitê de Ética em Pesquisa da Escola Nacional de Saúde Pública Sergio Arouca, protocolo no 219/10. 


\section{Resultado e discussão}

Os resultados serão apresentados a partir de três categorias: "Perspectiva histórica e cenário agrícola atual: do pêssego ao fumo"; "Políticas públicas para a diversificação agrícola: o prescrito e o real" e a "Produção diversificada e ecologicamente responsável". Procurou-se reconstituir o histórico e panorama atual da produção agrícola da localidade, buscando compreender os aspectos que a levaram ao cultivo do fumo e a repercussão do trabalho, no cotidiano das famílias nele envolvidas. Considera-se que as concepções, assim com as visões de mundo, vinculam-se à subjetividade, referindo-se a construções sociais para explicar fenômenos e processos a partir das experiências vividas (GEERTZ, 2008; MINAYO, 2007).

\section{Perspectiva histórica e cenário atual: do pêssego ao fumo}

Os depoimentos dos entrevistados revelaram uma história de cultivo de produtos agrícolas diversificados para o consumo familiar e venda do excedente. As atividades de maior volume comercial, historicamente nessa comunidade, centravam-se em um único produto, o pêssego. No entanto, o frágil poder de negociação, por parte dos agricultores, junto às indústrias, e a dependência da lei de oferta e demanda levaram ao abandono desse cultivo. Segundo relatos, quando havia pouca oferta de pêssego no mercado, o produto era bem pago e quando havia uma supersafra, favorecida especialmente pelas condições climáticas, as empresas eram mais rígidas em relação à classificação de qualidade do produto e não compravam toda a safra. Pêssegos classificados pela indústria como de segunda ou terceira classe não eram pagos, nem devolvidos ao produtor, chegando a $20 \%$ do produto enviado. Além destas razões, a indústria não efetuava o pagamento no mesmo ano, ou seja, protelava-a para o ano seguinte, sem atualização monetária. Desta forma, os agricultores viam-se, obrigados a entregar seu produto para a mesma indústria para receber a safra anterior. Além disso, para à compra dos insumos para a lavoura, no comércio local, era necessário pagamento à vista ou, caso contrário, acarretaria juros.

A dependência na comercialização à indústria, que mantinha o controle dos preços, ocorria por diversos fatores, como presença de poucas empresas, predomínio do plantio do pêssego e falta de perspectiva para um protagonismo desses agricultores. Quando as indústrias de pêssego fecharam e as de fumo 
passaram a predominar na região, os problemas antigos continuaram a existir,

mas com a esperança de obtenção de renda melhor e garantida pela indústria de parte das famílias de agricultores.

A formação de cooperativa que defendesse os interesses dos pequenos proprietários foi uma necessidade, dada a relação estabelecida com a indústria de pêssego. No entanto, trabalhar em cooperação nunca foi tarefa fácil. De acordo com o fundador e ativista da AAA, o fator histórico da emigração e as condições desfavoráveis em relação à posse da terra nos países de origem, como Alemanha ou Itália, contribuíram para uma relação mais individualista de trabalho para obtenção de melhores condições materiais. Apesar disto, existiam momentos em que as pessoas se reuniam para promover o trabalho coletivo e uma das ocasióes citadas pelo entrevistado era a organização de festas na comunidade:

As pessoas trabalham até uma semana de graça para a comunidade. Festas eles fazem muito bem e doam-se, mas quando é para trabalhar unidos num trabalho econômico, visando à libertação é mais difícil porque também o mecanismo no mercado hoje não é fácil (fundador e ativista da AAA).

Para este informante, outros fatores também dificultam o trabalho em cooperação: a permanência dos dirigentes de sindicatos e associações por muito tempo no poder, 15, 20 anos, impedindo a formação de novas lideranças; ausência de cooperativas para pequenos agricultores com a sua efetiva participação e distorção na remuneração dos trabalhadores da cooperativa, de forma que o integrante da gestão ganha mais do que o próprio agricultor.

Os aspectos negativos em relação ao cultivo e comercialização do pêssego quase levaram à substituição total desse cultivo pelo fumo, no final de 1990, o que ocorreu como uma possibilidade de mudança e de garantia de renda na região: "como deu essa queda no pêssego, o povo se desesperou e as fumageiras entraram na hora certa, o povo tava meio carente e a propaganda deles é boa, e é enganosa" (presidente da ACL).

De acordo com os entrevistados da Emater e Embrapa, ao mudar de cultivo os agricultores estão perdendo saberes referentes à cultura do pessegueiro, por exemplo, relacionados à poda e ao enxerto das mudas. Era comum os agricultores trabalharem em outras cidades e localidades próximas, desenvolvendo essas atividades. Outro prejuízo identificado pelos entrevistados era em relação ao processamento de frutas e verduras. Havia uma riqueza em transformar os produtos por eles produzidos em passas e conservas de forma artesanal. Hoje, 
os alimentos consumidos pelos agricultores são industrializados. Também foram relatadas mudanças no trabalho coletivo que ocorria em algumas comunidades, como assinalam dois entrevistados: "são mais raros os momentos de encontro na Associação ou na Igreja”. O cultivo do fumo mantém as famílias ocupadas o ano inteiro, num ciclo ininterrupto de trabalho, dificultando o convívio social.

As políticas públicas destinadas à população local, segundo os entrevistados, especialmente os representantes de organizações da sociedade, tinham forte componente assistencialista em sua execução. O núcleo de bem-estar social, pertencente à Secretaria de Administração do município, distribuía, nas localidades, alimentos, animais de pequeno porte como galinhas e porcos, na maioria doados por candidatos que visavam à reeleição. Havia, ainda, a distribuição de sementes e patrulhas agrícolas.

As patrulhas agrícolas eram tratores que ficavam disponíveis, tendo um motorista para o trabalho, sendo geridos pelas associaçóes locais. A gestão do trabalho coletivo era uma tarefa difícil de conciliar, principalmente quando ocorriam avarias no trator, pois as associaçóes não estavam capitalizadas para arcar com o conserto, nem as famílias que utilizavam o equipamento, ou aquelas que iriam receber seus serviços. Geradores de discórdias, a maioria dos tratores foi vendida e o dinheiro empregado para melhorias das associações.

Hoje em dia, os entrevistados são unânimes em dizer que houve mudanças na localidade: "dificilmente se vê um homem a cavalo, tem muitas motos na localidade" (extensionista rural). Relembraram, ainda, que as mudanças se estendem ao comportamento das pessoas, antes vistas como "um povo sofrido", "que falava muito alto". Hoje "parecem mais civilizados", dirigem-se às repartiçôes para resolverem seus problemas como qualquer outro produtor rural.

Atualmente, é do cultivo do tabaco que provém a maior fonte de arrecadação do município estudado, conforme os entrevistados. A dependência econômica dos municípios produtores pode levá-los em breve a um declínio econômico (BEACH; JONES; TOOZE, 2008). De um lado, o crédito facilitado e o apelo do mercado às inovações tecnológicas e de consumo aumentaram o poder de compra dos fumicultores e, consequentemente, seu endividamento. Por outro, a queda nas exportaçóes e no consumo de tabaco, devido ao plantio em países africanos, a oscilação cambial e as medidas da Convenção-Quadro devem interferir na cadeia produtiva do fumo. Gestores municipais atentos a este cenário 
estão liderando iniciativas de diversificação agrícola junto às comunidades rurais, inaugurando outras formas de cultivo e comércio dos produtos (BRASIL, 2010).

\section{Política pública para a diversificação agrícola: o prescrito e o real}

Os programas dos governos do estado e federal para os agricultores que cultivam tabaco e desejam investir em outras atividades em suas propriedades foram enumerados pelo extensionista rural 1: no âmbito estadual foram mencionados o Fundo de Financiamento para Pequenos Produtores Rurais (FEAPER) e projetos desenvolvidos pela Emater para aquisição de mudas, de microaçudes e de equipamentos para fruticulturas. Do Governo Federal, foi apontado o Programa Nacional de Fortalecimento da Agricultura Familiar (PRONAF). Esses programas possuem diferentes linhas de crédito com juros baixos e subsidiados (BRASIL, 2010).

A política de aquisição da merenda escolar foi lembrada por três dos representantes da sociedade (STRs e UAC) como iniciativa de diversificação, alavancando a agricultura familiar, resgatando ou modificando hábitos alimentares dos educandos e das famílias produtoras, bem como demandando uma (re) organização da produção, para garantir a regularidade dos produtos. A implantação dessa política, para esses informantes, rompe com uma rede consolidada de empresários municipais, estimula o plantio sem agrotóxicos, pois para a merenda escolar é recomendado que os produtos não tenham resíduos. E o pagamento tem superado o que a indústria pagava a essas famílias.

O Programa Nacional de Alimentação Escolar (PNAE) foi criado, no Brasil, por meio da Lei no 11.947/2009, ficando determinada a utilização de, no mínimo, $30 \%$ dos recursos repassados pelo Fundo Nacional de Educação (FNDE) para alimentação escolar, mediante compra de produtos da agricultura familiar, priorizando os assentamentos de reforma agrária, as comunidades tradicionais indígenas e quilombolas (BRASIL, 2010). Nesse sentido, esta política garante o mercado para os alimentos in natura ou processados pela agricultura familiar.

No entanto, houve resistência, no município estudado, em executar a política da merenda escolar com os recursos do governo federal: "no ano passado teve três vezes a licitação, sempre tinha um erro, chegava na hora, abria o envelope, bah, tem erro, então foi difícil" (representante UAC). De acordo com esse informante, por 
pressão dos movimentos sociais integrantes dos Conselhos Municipais, as questões da merenda escolar e outras políticas agrícolas têm sido discutidas, embora nem sempre com resultados satisfatórios: "são espaços de conflito, de disputa entre o poder público e as organizações dos agricultores, tentando se apropriar do processo" (Representante UAC). Aparentemente, havia pouca vontade do Poder Público municipal em modificar o modo de "fazer política", de modo a favorecer a agricultura familiar, como no exemplo do fornecimento da merenda escolar.

Do ponto de vista tecnológico, houve desenvolvimento na agricultura, mas os trabalhadores rurais da localidade estudada têm baixa escolaridade. Segundo as professoras da escola local, 30\% dos pais e mães dos alunos são analfabetos e apenas dois têm ensino médio. Alguns agricultores mantêm a lavoura da mesma forma que há 30 anos, utilizando uma grande extensão de terra para pouca semente, gerando baixa produção. Ao mesmo tempo, o mercado se apresenta cada vez mais sofisticado e aberto à importação, por exemplo, da cebola, do Chile e do pêssego, da Grécia. Em relação a novas tecnologias, para o presidente da associação local falta informação: “às vezes tem muita coisa passando bem pertinho da gente e a gente só vai saber depois que já passou, coisas às vezes muito boa, muito criativa" (Presidente da ACL).

No depoimento de um Extensionista Rural da Emater sobre inovaçôes tecnológicas na agricultura, parece haver falhas na comunicação entre os agricultores e o responsável pela assistência técnica:

O agricultor não acha importante tá, porque ela existe [a assistência técnica]. Só que ainda tem aquela resistência que o produtor se sente ainda pela limitação intelectual dele, ele não quer trocar experiência com um técnico, ele não quer expor os problemas que tem, ele não quer enxergar a sua problemática pra chegar às melhorias. (Extensionista Rural 1).

Como sabiamente Paulo Freire discute em seu livro Extensão ou comunicação?, escrito em 1968, no Chile, o trabalho com os agricultores precisa extrapolar o treinamento de técnicas do semeio, colheita ou reflorestamento, para um estar com. Mecanismos históricos e de cultura medeiam as relações homem-natureza, e a aproximação deste saber-fazer ocorre por meio do diálogo. Quais seriam as razões do silenciamento, da apatia dos agricultores ou do não aproveitamento da assistência técnica? As respostas podem estar em nossa herança histórica antidialógica, do latifúndio implicando camadas sociais hierárquicas de menor ou maior valor, com relaçôes rígidas e verticais, sem experiência participativa (FREIRE, 2011). 
Um segundo informante da Emater exemplificou a dificuldade em propor mudanças ou melhorias. O projeto de diversificação agrícola foi posto em prática com um agricultor que plantava fumo e desejava substituir seu plantio. Foram adquiridos materiais para o plantio e irrigação de legumes: com nove mil reais compraram motor-bomba, canos, mangueiras e pulverizador e até mercado para os produtos foi acertado, havendo, no entanto, outras dificuldades:

Quando eu fiz o projeto pra ele eu não pensei que ele não tinha, ele não tem carteira, ele não tem carro, e aí produzimos um monte de cenoura e não tinha como trazer. Ele produziu mas, esbarrou, tem alguma coisa, que às vezes a gente não pensa, e as pessoas como eu tava te dizendo a cultura deles não vai além, não adianta, tu quer, mas não... Parece que são pessoas que precisam ser dirigidas (extensionista rural 2).

Diferentemente do sistema integrado no cultivo do tabaco, em que a indústria fornece insumos, equipamentos, assistência técnica e compra do produto final, a diversificação em pequenas propriedades rurais requer um trabalho processual, contínuo e qualificado, de debate, planejamento e acesso a políticas públicas de caráter estruturante, como crédito, assistência técnica, capacitação, logística e espaços para a comercialização dos produtos, visando ao fortalecimento da organização rural e da intersetorialidade (BRASIL, 2010). Tais aspectos precisam ser levados em conta ao se propor a diversificação. A diversificação agrícola exige investimentos e é também uma opção política: um projeto para se trabalhar coletivamente com mudanças nas relaçõos de produção, comércio e consumo e, certamente, nas relações de poder.

Conforme assinalaram dois representantes da sociedade (CAPA e associação local), o investimento em outro cultivo não passa apenas pela conscientização: "a cultura do fumo está enraizada aqui no município”. Em pequenas propriedades, o tabaco destaca-se pela produtividade e valor comercial, quando comparado a batata, feijão ou leite, por exemplo. E os agricultores alegam que, apesar do trabalho exaustivo, ainda é o que lhes permite maior margem de lucro. A representante do CAPA explicou que a diminuição do cultivo do tabaco é lenta. Alguns agricultores interromperam as atividades devido à falta de força de trabalho familiar, aos custos na contratação de diaristas ou à aposentadoria. Por outro lado, observou-se, no estudo, que por trás desse discurso propagado pela indústria e internalizado pelos agricultores, em relação a ganhos e lucro garantidos propiciados pelo cultivo do tabaco, há o endividamento, a perda de autonomia do agricultor e, em médio longo prazo, a queda da produtividade, pelo desgaste do solo. 
Em relação à situação atual do plantio de tabaco, seja de aumento ou estagnação, um dos instrutores da indústria fumageira relatou que depende da região, e de forma geral há certo equilíbrio. Por exemplo, na localidade estudada, houve aumento desse cultivo, enquanto em outras, diminuiu: "tem agricultores desistindo da cultura ou até diminuindo, isso é peculiar de cada região, então isso muda muito" (instrutor da indústria 1). O segundo instrutor disse que se um produtor desiste do plantio de tabaco a decisão é aceita sem problemas, pela indústria: "as pessoas sabem o tempo de parar". Para os entrevistados, a maior razão de cessar o cultivo é quando os agricultores se aposentam.

Os representantes do sindicato dos trabalhadores rurais reconhecem que há um movimento, no Brasil, para diminuir a produção do tabaco. No entanto, eles, da mesma forma que o presidente da Associação local e a do CAPA, acreditam que se houver incentivo do governo à agricultura familiar, subsídio para os produtos, as pessoas substituirão a cultura do fumo: "ninguém proibiu plantar feijão, milho para pode plantar o fumo, então ele tem que ter opção; como é que eu vou manter o agricultor lá produzindo sem renda?” (RSTR).

O representante da Embrapa alertou que, no cenário atual, para diversificar é necessário modificar certas estruturas, como o mercado, o crédito, a assistência técnica, porque às vezes as pessoas não sabem como começar uma nova alternativa. Então tem que ser um conjunto orquestrado de ações, desde motivação para a diversificação, até o planejamento e execução junto aos agricultores. Mas são medidas que têm que ser tomadas com certa urgência. $O$ fluxo de agricultores, na Embrapa, buscando informações, é muito grande. Grupos de fumicultores têm sido organizados, nos municípios, pela Emater, prefeituras e outras entidades que trabalham com agricultura familiar para visitar e conhecer o trabalho de diversificação proposto pela Embrapa. Outra grande dificuldade, segundo o entrevistado, deve-se à perda da tradição de cultivar alimentos. No meio rural, agora, há caminhões vendendo verdura, leite e até pão. Então, como mudar esta realidade? Não é de um dia para o outro, tem que ser construído; eles têm que ter sementes, mudas e têm que se programar. Para esse informante, o êxito do pequeno agricultor vem da agricultura familiar:

O grande sucesso da agricultura familiar é quando ela é diversificada, aumenta a rentabilidade e a estabilidade; sempre foi o princípio da agricultura familiar diversificada por natureza. Nos últimos tempos começou a adotar esse mesmo cultivo, o monocultivo do fumo é que meio comprometeu a coisa (EMBRAPA). 
Para este representante do Estado, para superar esse problema a questão não é apenas técnica; é preciso uma política pública emergencial. Há agricultores passando fome por esse impasse do cultivo do fumo, famílias com dificuldades para se alimentar:

Em alguns municípios da região sul do estado e também de Santa Catarina, os agri-
cultores começaram a bater na porta da prefeitura, não têm o que comer, aí os prefei-
tos começam a se preocupar, $90 \%$ das caravanas têm vindo com o prefeito e vereado-
res preocupados com a questão do meio rural. (EMBRAPA).

Nesse cenário, há ainda o movimento da indústria fumageira em divulgar seu papel de empresa socialmente responsável e de estimular a diversificação agrícola. Como chamou a atenção o representante do MPA, a indústria do tabaco tem se engajado em campanhas de responsabilidade social. Essas empresas já investem no "econegócio" e, após 40 anos de produção agroquímica, veem agora uma nova possibilidade de investimento, mantendo convênio até mesmo com empresas públicas como Emater/RS e apoio institucional em campanhas do Estado do Rio Grande do Sul (SOUZA CRUZ, 2010). Interessa-lhes o status de uma empresa que trabalha em harmonia com o ambiente, apesar de manter o modelo tecnológico que faz com que o agricultor trabalhe utilizando intensivamente agrotóxicos. Mas falar em defesa do ambiente lhes renderá maior credibilidade e reconhecimento social e, rapidamente, procuram ocupar esse espaço. Estudo desenvolvido na Inglaterra referente a estratégias de responsabilidade social da British American Tobacco (BAT) revelou que seu objetivo era ter acesso à elite política daquele país e assim influenciar nas decisões (FOOKS et al., 2011).

Localmente são comuns essas parcerias por parte da indústria do tabaco, seja no apoio a eventos ou ainda atuando em conjunto com órgãos públicos. Tal aproximação não é uma estratégia recente, como contou o líder local 1. Há mais de 20 anos, uma empresa fumageira foi parceira na horta escolar, fornecendo sementes e distribuindo-as entre as famílias dos escolares. Havia também o "clube da árvore" em que as mudas de árvores eram destinadas ao horto florestal municipal e aos escolares. As crianças eram estimuladas a fazer redação sobre o tema e havia banners na escola com propaganda da indústria e da campanha que apoiavam. Os efeitos da propaganda das grandes indústrias, no imaginário dessas crianças e de suas famílias, como uma empresa amiga da árvore, do verde e preocupada com a qualidade da alimentação das pessoas, certamente contribuíram para a adesão ao plantio do fumo, sem maiores críticas a tal prática por parte da Comunidade. 
Desde 1988, a Philip Morris buscou cativar o público infantil com a introdução de Joe Camel nas propagandas de cigarro, nas quais um camelo semelhante a um desenho animado aparecia fumando e vestindo diferentes trajes simpáticos ao público infantil (BREO, 1993). Para Boeira e Guivant (2003), a Tecnociência aplicada à nicotina inclui a publicidade direta e indireta. Programas como as Hortas Escolares e o Clube da Árvore constituem peças de uma dinâmica rede estratégica que vincula instrumentalmente ao tabaco, de forma crescente e complexa, o espaço-tempo do corpo-cérebro, do local, do regional, do nacional e do global.

Atualmente, conforme sinalizam Boeira e Johns (2007), a histórica relação de confiança entre governo e a indústria de tabaco parece rompida, tendo em vista a atuação da sociedade civil internacional, da OMS e da rede antifumo. Com o primeiro Tratado Mundial de Saúde Pública, vislumbra-se a oportunidade do exercício de outras relaçôes entre sociedade civil, governo brasileiro e a indústria do tabaco.

No município estudado, iniciativas estão sendo concretizadas, estimuladas ou ainda planejadas para a diversificação agrícola. Algumas, com o envolvimento da sociedade e parceria do Estado, como no caso de uma cooperativa que atualmente conta com 500 agricultores e trabalha com frutas, principalmente o pêssego. Uma seleção prévia das frutas é realizada para posterior envio à indústria, e aquelas que são reprovadas nessa seleção são aproveitadas pela própria cooperativa para sucos e pessegadas. Tanto a comercialização para a indústria, como o beneficiamento pela cooperativa vêm se diversificando com produtos como morango, abóbora e pepino. A cooperativa está propondo, nas assembleias, que a produção seja livre do uso de agrotóxicos.

A UAC está estimulando a produção do leite e sucos de fruta. O sindicato dos trabalhadores rurais está propondo ao Executivo Municipal a "pecuária familiar": as famílias criariam os animais, que seriam abatidos em um abatedouro municipal ou regional e a comercialização poderia ser efetuada por meio de uma cooperativa.

\section{A produção diversificada e ecologicamente responsável}

Incentivar e promover a retomada da agricultura diversificada e ecologicamente responsável, entre fumicultores e demais agricultores que utilizam agrotóxicos em seus cultivos, configura um desafio ao Poder Público e à sociedade. A herança 
brasileira de uma agricultura colonial monoculturista e exportadora, aliada aos apelos da "Revolução Verde" de modernização agrícola e potencialidade de produzir mais com melhor qualidade e competitividade internacional, por meio de um pacote tecnológico, incluindo agrotóxicos, sementes e fertilizantes, compõem um cenário adverso a iniciativas ecologicamente responsáveis (GEHLEN, 2004; AUGUSTO, 2012). Como exemplo dessa prática por parte do próprio governo, em 1976 foi implementada a política da Defesa Nacional Agrícola na qual os agricultores compravam uma cota de agrotóxicos na obtenção do crédito rural (AUGUSTO, 2012). Com essa política, a utilização de agrotóxicos aumentou e a produção agrícola tornou-se dependente deles, atingindo a quase extinção de práticas ecologicamente saudáveis, no manejo do solo, controle de pragas e no cultivo de sementes crioulas.

Wezel et al. (2009) discutem a evolução histórica nos diferentes usos do conceito de Agroecologia em países como Alemanha, Brasil, Estados Unidos e França. Em 1930, era discutido como uma disciplina científica preocupada com a produção agrícola. Atualmente, sua abordagem incorpourou elementos de movimento e prática social, enfatizando questôes ambientais, sociais, econômicas e éticas para resolver os desafios da produção agrícola.

Um dos entrevistados, membro da Associação de Agroecologistas da Região Sul, enfatizou que a decisão em abandonar o cultivo dependente de agrotóxicos foi tomada após intoxicação:

\footnotetext{
Nós tinha colocado o veneno uns dois dias antes e nós tava colhendo pêssego e comecei a ficar com dor de cabeça, ânsia de vômito e já apagou tudo, acordei num quarto de hospital dois dia depois. Na mesma época nasceu meus filhos [gêmeos] em 88. Então, quando surgiu essa proposta de trabalhar sem o químico eu entrei até fui um dos primeiros na região, nesse trabalho (membro da Associação Arpa-Sul).
}

Ele referiu que a associação foi criada em 1995 com o objetivo de suprimir o intermediário, auxiliando os agricultores a comercializar a produção ecológica. Inicialmente, 29 famílias faziam parte da associação. Nesse primeiro ano, muitas foram as dificuldades: o acesso era difícil para os que queriam comprar; os agricultores não tinham produção suficiente para abastecer a feira; a qualidade não era boa. Posteriormente, quando havia produção, não havia consumidor, principalmente porque as pessoas não conheciam o produto agroecológico. Diversas vezes ele carregou o caminhão para a feira, ao meio dia carregava-o de volta, e então, com as sobras, alimentava os animais. Assim, muitas famílias 
abandonaram a produção agroecológica. Dois anos depois da inauguração da Associação é que se estabilizou a produção, melhorando as condições da terra, a qualidade dos produtos e sua variedade.

Por meio de uma pesquisa, foi avaliado o uso de técnicas agroecológicas pela produção familiar na Região Centro-Sul do Estado do Paraná (ASSIS; ROMEIRO, 2005), concluiu-se a respeito da importância da atuação do Poder Público para o desenvolvimento da Agroecologia, com políticas específicas voltadas para difusão de práticas agroecológicas, como crédito agrícola adaptado à realidade da produção agrícola familiar, assistência técnica capacitada em Agroecologia e implementação de mecanismo que propiciem a viabilidade de comercialização, aproximando produtores e consumidores, reduzindo o espaço de atuação de intermediários. Para Blanc e Kledal (2012), é necessária a atuação do Estado no apoio às operaçōes de mercado que garantam legitimidade, a longo prazo, na produção de alimentos orgânicos, no crescimento econômico e na estabilidade social.

Segundo o membro da Associação Arpa-Sul, atualmente 38 famílias fazem parte dessa associação, em cinco municípios da "Metade Sul” do Rio Grande do Sul. Ele define seu trabalho da seguinte maneira:

É uma mudança de mentalidade, é uma filosofia de vida, a gente vê cifras por que é necessário, necessito pagar minhas contas, só que com o meu trabalho, hoje eu to com quinze anos de atividade, eu digo que eu to muito melhor em qualidade de vida que muita família que planta fumo há quinze, dezesseis anos, também. A gente tem um respeito muito grande pela nossa rede de consumidores, tem um vínculo de amizade, a maioria dos consumidores nossos, eles conhecem a lavoura onde é produzido o produto, eles vem fazer visita.

Mais do que mudar práticas agrícolas baseadas em um modelo agroquímico e de monocultura, o enfoque agroecológico trata de mudanças políticas, econômicas e socioculturais. Na medida em que a transição agroecológica implica não somente maior racionalização econômico-produtiva, com base nas especificidades biofísicas de cada agroecossistema, também propõe mudanças nas atitudes e valores dos atores sociais com respeito ao manejo e conservação dos recursos naturais e nas relações sociais entre os atores implicados (CAPORAL; PAULUS; COSTABEBER, 2009).

Para esses autores, a Agroecologia integra saberes populares e conhecimentos técnico-científicos, numa perspectiva epistemológica desafiadora do paradigma convencional e reducionista que separa o homem da natureza e que estuda as 
partes com a ilusão de que assim entenderá o todo. O enfoque agroecológico é uma ação dialética transformadora, parte do conhecimento local, respeitando e incorporando o saber popular e busca integrá-lo com o conhecimento científico (CAPORAL; PAULUS; COSTABEBER, 2009).

Observou-se, nas entrevistas com os agricultores do tabaco, certo constrangimento quando eram abordadas as consequências do uso do tabaco à saúde humana. Embora grande parte não fume, eles diziam que procuravam não pensar nestas questôes e justificavam sua opção pelo plantio do fumo devido à pouca valorização comercial de produtos como milho e feijão. Quando eram discutidos os riscos à saúde do agricultor e a exposição aos agrotóxicos, eles alegavam que nos demais cultivos como batata, tomate e pêssego eram utilizados tanto ou mais agrotóxicos que o tabaco. Para Benson (2010), quando cada agricultor está apenas preocupado com sua estratégia de sobrevivência, ele não desenvolve um olhar mais amplo sobre o contexto. No entanto, instalar um sentimento de culpa pode minar a capacidade para o comportamento solidário. $\mathrm{O}$ que o autor sugere é explorar outras abordagens mais abrangentes, favorecendo a compreensão do quadro social e político em que diferentes atores estão inseridos.

Ao avaliarem as estratégias na agricultura familiar de diversificação, por meio da viabilidade econômica e cultivos alternativos ao fumo na Região do Vale do Rio Pardo-RS, Vargas e Oliveira (2012) constataram que em relação ao tamanho médio das propriedades, as famílias que produzem fumo possuem menos hectares de terra do que as famílias que não o fazem. Consequentemente, arrendam mais terras e $28,4 \%$ dos fumicultores trabalham exclusivamente em terras arrendadas.

Em nosso cenário de estudo também foi observado este fato. Um dos agricultores entrevistados afirmou que a alternativa do cultivo do tabaco deu-se pela falta de alternativas:

Por enquanto não tem outra alternativa pra pessoa sobreviver quem tem pouca terra, agora que tem bastante terra, ainda pode criar animal, pode plantar bastante milho e feijão. Quem tem 10 hectares de terra pode viver bem na colonia, isso eu posso lhe garantir, seu eu tivesse 10 hectares de terra não plantava fumo, mas eu tenho 5 hectares e duas famílias pra sobreviver (Família 1).

Para o fundador e ativista da Associação de Agricultores e Apicultores, a pequena propriedade é uma "incógnita": como viver e plantar bem, assim como diversificadamente com menos de 20 hectares? O Programa Nacional de Crédito Fundiário foi uma possibilidade apresentada pelos representantes do Sindicato 
dos Trabalhadores Rurais como uma oportunidade de os agricultores com pouca terra adquirirem mais. No entanto, foi ressaltada a dificuldade em pagar tal financiamento sem o plantio do tabaco:

Quem não planta fumo tá lascado, tanto é que tem agricultores que adquiriram terra pelo banco da terra, pelo crédito fundiário e estão com dificuldade de pagar a prestação das terras, a maioria que não planta fumo, a coisa não é fácil, e o fumo dá retorno. Até a gente orienta bem a pessoa quando vai adquirir "olha no momento atual é difícil pagar a prestação da terra com milho e feijão, então analisa bem com a família em casa, conversem, se organizem", se vão plantar fumo é uma alternativa que eles podem pagar a prestação, mas sempre nós orientamos que não deixem de plantar as outras coisas.

No estudo de Vargas e Oliveira (2012), também foi observado o interesse limitado ou inexistente entre representantes locais do Estado ou da sociedade organizada em liderar e incentivar programas de substituição ao cultivo do tabaco e a diversificação agrícola em Regiōes com grande produção de fumo. Tais atitudes de resistência à diversificação, neste estudo, foram observadas nos depoimentos sobre as dificuldades em executar a Política da Merenda Escolar ou, ainda, no pagamento do crédito fundiário.

O discurso desses atores sobre a necessidade de cultivar outros produtos além do tabaco constou da fala dos representantes do sindicato e foi assinalada pelos representantes da indústria que "se ele não plantar um feijão, batata, criar galinha, porco, não vale nem a pena plantar fumo. As empresas têm programas para diversificar a plantação, é uma exigência do mercado" (instrutor da indústria 3).

Apesar desses "incentivos à diversificação", a renda dos agricultores que produzem fumo é praticamente exclusiva desta atividade (VARGAS; OLIVEIRA, 2012). E quando os autores compararam a receita bruta anual dos agricultores, observaram que a dos fumicultores é cerca de três vezes maior do que a dos que não plantam fumo, sendo que a receita líquida dos fumicultores é menor.

A relação estabelecida entre agricultores e indústria do fumo não é simples de ser rompida. Quando endividados, os agricultores sempre têm a esperança de saldá-la na próxima safra, o que invariavelmente acaba não acontecendo. Pelo contrário, a dívida aumenta e sua contestação na justiça é caso quase sempre perdido. Para ocorrer a diversificação, é necessário um tempo de investimento no crescimento de outros cultivos, o que pode significar diminuição na obtenção imediata de lucro. Por isso se fazem necessárias políticas que acompanhem os agricultores nesta transição, até mesmo com auxílio financeiro. 
A proposta do sistema integrado para o tabaco e outras atividades, como nos casos da produção de frango e suínos, para o representante do MPA, é acompanhada de muitas incertezas. As famílias que aderem a essa relação de trabalho estão vinculadas a empresas multi ou transnacionais e não possuem nenhum vínculo empregatício, não sabem ao certo quanto ganharão ao final da produção, mas apenas que precisam produzir e entregar para as mesmas. Além disso, o sistema integrado interfere na cultura local, desestruturando a produção diversificada e de subsistência, estimulando a monocultura.

Muitos são os elementos que dificultam a diversificação agrícola: as pequenas propriedades, o apego a cultivos tradicionais como milho e feijão e a inexistência da experimentação de outros cultivos mais rentáveis comercialmente, como aqueles desenvolvidos pela Embrapa Clima Temperado, como a minimelancia ou os cítricos sem sementes que foram apresentados pelo representante da Embrapa. Vê-se, ainda, que no cultivo do fumo, pelas características de intensificação da força de trabalho, aliada a um ciclo ininterrupto de atividade, a possibilidade de diversificação agrícola e não agrícola das famílias fica comprometida.

Acredita-se que a lógica produtivista que sustenta a monocultura minou a possibilidade da ecologia de saberes, que se originam da diversidade e da globalização contra-hegemônica entre os agricultores do tabaco, a qual precisará ser resgatada. A busca dessa ecologia é a procura pela emancipação das pessoas, quebrando a dependência produtiva e econômica, que se estende à natureza. $\mathrm{Na}$ monocultura, agricultores e natureza ficam dependentes de produtos agroquímicos e os agricultores, reféns economicamente, da indústria, como no sistema integrado. Na ecologia das produtividades, a lógica produtivista dá lugar à valorização dos sistemas alternativos de produção, das organizações econômicas populares, das cooperativas, das empresas autogeridas, da economia solidária, maneiras de viver e plantar que a "ortodoxia produtivista capitalista ocultou ou descredibilizou” (SANTOS, 2006, p. 105).

\section{Considerações finais}

As estratégias de diversificação agrícola apontadas pelos informantes do Estado foram os programas estaduais e federais de crédito, assistência técnica e o trabalho de pesquisa proposto pela Embrapa Clima Temperado. Os representantes de organizações da sociedade civil reconheceram o Programa 
Nacional de Alimentação Escolar como potencialidade à diversificação, assim como a cooperativa que trabalha com a comercialização e beneficiamento de frutas e também a Associação de Agroecologistas, que auxilia a comercialização da produção. Eles defendem que deve haver mais incentivo à agricultura familiar. Como desafios à diversificação, estão as parcerias, por parte da indústria do tabaco, com órgãos públicos, as características fundiárias da região com minifúndios rurais de 0,5 a 20 hectares de terra e as dificuldades em quitar dívidas junto ao Programa Nacional de Crédito Fundiário com cultivos diversificados. Para os representantes da indústria do tabaco, as empresas têm programas e estimulam a diversificação da plantação.

Embora tenham sido identificadas iniciativas por parte do Poder Público e da sociedade organizada, elas não atingem os fumicultores pesquisados. As políticas públicas são potencializadoras da diversificação por meio de crédito e assistência técnica, mas sua execução em nível local é desafiadora. Os múltiplos interesses locais dificultam ou impedem que os agricultores tenham acesso às políticas propostas pelos governos estadual e federal, como exemplificado no PNAE, em que frequentemente ocorrem problemas na abertura de licitaçôes, impedindo o avanço do processo ou, ainda, em iniciativas de diversificação que "esbarram" na comercialização, como dificuldades de transporte ou de mercado consumidor.

Nesteestudo, nadiscussãoapresentadafoiconsideradoo enfoquenadiversificação agrícola como alternativa ao cultivo do fumo, na visão dos diferentes atores e suas repercussões na melhoria da saúde e qualidade de vida dos trabalhadores rurais, na perspectiva do conceito ampliado de saúde como resultante das condições do ambiente, trabalho, acesso e posse de terra, dentre outros aspectos. Jackson et al. (2013) recomendam a integração da abordagem da promoção da saúde e dos determinantes sociais de saúde como forma de desenvolvê-la em todas as políticas públicas. Assim, a intersetorialidade deveria ser exercida, desde a discussão dos gastos em saúde, no debate a respeito da degradação ambiental ou da promoção de Justiça Social, por meio do desenvolvimento sustentável, garantindo melhores condiçôes para a equidade em saúde.

Por fim, segundo argumentou o representante da Embrapa "para diversificar é necessário modificar certas estruturas, como o mercado, o crédito, a assistência técnica, porque, às vezes, as pessoas não sabem como começar uma nova alternativa”. Portanto, é essencial resgatar o saber e a autonomia dos agricultores, 
ao mesmo tempo em que se estimulam práticas de trabalho em cooperação,

assim como é preciso revitalizar políticas públicas estruturantes como a reforma agrária e o crédito. O êxito da CQCT na redução do cultivo do fumo, por meio da diversificação agrícola e proteção ao ambiente e à saúde de trabalhadores, passa pelo resgate e fortalecimento da agricultura familiar, na busca de melhores condiçôes de vida e saúde, em harmonia com a natureza. ${ }^{1}$

\section{Referências}

ASSIS, R.L.; ROMEIRO, A.R. Agroecologia e Agricultura Familiar na Região Centro-Sul do Estado do Paraná. RER, v. 43, n. 1, p. 155-177, 2005.

AUGUSTO, L.G.S. Agrotóxicos: nuevos y viejos desafios para la salud colectiva. Salud Colectiva, v. 8, n. 1, p. 5-8, 2012.

BEACH, R.H.; JONES, A.S.; TOOZE, J.A. Tobacco Farmer Interest and Success in Income Diversification. Journal of Agricultural and Applied Economics, v. 40, n. 4, p. 53-71, 2008.

BENSON, P. Giants in the Fields: Agribusiness and Farm Labor Politics in the United States. Anthropology of Work Review, v. 31, n. 2, p. 54-70, 2010.

BLANC, J.; KLEDAL, P.R. The Brazilian organic food sector: Prospects and constraints of facilitating the inclusion of smallholders. Journal of Rural Studies v. 28, p. 142-154, 2012. BOEIRA, S.L.; GUIVANT, J.S. Indústria de tabaco, tabagismo e meio ambiente: as redes ante os riscos. Cadernos de Ciência \& Tecnologia, v. 20, n. 1, p. 45-78, 2003.

BOEIRA, S.L.; JOHNS, P. Indústria de Tabaco vs. Organização Mundial de Saúde: um confronto histórico entre redes sociais de stakeholders. Revista Internacional Interdisciplinar Interthesis, v. 4, n. 1, p. 1-25, 2007.

BRASIL. Açôes do Ministério do Desenvolvimento Agrário para a diversificação da produção e renda em áreas cultivadas com tabaco no Brasil. Brasília: Ministério do Desenvolvimento Agrário, 2010.

BREO, D.L. Kicking Butts - AMA, Joe Camel, and the 'black-flag' war on tobacco. JAMA, v. 270 , n. 16 , p. $1978-1984,1993$.

CAPORAL, F.R.; PAULUS, G.; COSTABEBER, J.A. Agroecologia: uma ciência do campo da complexidade. Brasília, 2009.

FOOKS, G.J. et al. Corporate Social Responsibility and Access to Policy Élites: An Analysis of Tobacco Industry Documents. PLoS Medicine, v. 8, n. 8, p. 1-12, 2011.

FREIRE, P. Extensão ou comunicação? São Paulo: Paz e Terra, 2011.

GEERTZ, C. Nova luz sobre a antropologia. Rio de Janeiro: Jorge Zahar, 2001. 248p. . A interpretação das culturas. Rio de Janeiro: LTC, 2008. 324p. 
GEHLEN, I. Políticas públicas e desenvolvimento social rural. São Paulo em Perspectiva, v. 18, n. 2, p. 95-103, 2004.

JACKSON, S.F. et al. A. Synergy for health equity: integrating health promotion and social determinants of health approaches in and beyond the Americas. Rev Panam Salud Publica, v. 34, n. 6, p. 473-80, 2013.

LOKER, W.M. The rise and fall of flue-cured tobacco in the Copán Valley and its environmental and social consequences. Human Ecology, v. 33, n. 3, p. 299-327, 2005.

MINAYO, M.C.S. O desafio do conhecimento. São Paulo: Hucitec, 2007.

ORGANIZACIÓN MUNDIAL DE LA SALUD. Convenio marco de la OMS para el control del tabaco. Ginebra: OMS, 2004. Disponível em: http://www.whqlibdoc.who.int/ publications/2003/9243591010.pdf.

- Declaração Politica do Rio sobre Determinantes Sociais da Saúde. Conferência Mundial sobre os Determinantes Sociais da Saúde. 19-21 de outubro de 2011, Rio de Janeiro. Disponível em: http://www.who.int/sdhconference/declaration/Rio_political_ declaration_portuguese.pdf?ua $=1$

PUSHKARSKAYA, H.; MARSHALL, M.I. Family Structure, Policy Shocks, and Family Business Adjustment Choices. J Fam Econ, v. 31, p. 414-426, 2010.

RIQUINHO, D.L.; HENNINGTON, E.A. Health, environment and working conditions in tobacco cultivation: a review of the literature. Ciência \& Saúde Coletiva, v. 17, n. 6, p.1587$1600,2012$.

SANTOS, B. S. A Gramática do tempo: para uma nova cultura política. Para um novo senso comum. A ciência, o direito e a política na transição paradigmática, volume IV. Porto: Edições Afrontamento, 2006.

SOUZA CRUZ. O Produtor de tabaco: meio ambiente legal. Souza Cruz, 2010.

VARGAS, M. A.; OLIVEIRA, B. F. Estratégias de Diversificação em Áreas de Cultivo de Tabaco no Vale do Rio Pardo: uma análise comparativa. RESR, v. 50, n. 1, p., 175-192, 2012. VARGAS, M. A.; BONATO, A. Cultivo do tabaco, agricultura familiar e estratégias de diversificação no Brasil. Brasília: Ministério do Desenvolvimento Agrário, 2007.

VELHO, G. Observando o familiar. In: NUNES, E.O. (Org.). A aventura sociológica: objetividade, paixão, improviso e método na pesquisa social. Rio de Janeiro: Zahar, 1978. p. 36-46.

WEZEL, A. et al. Agroecology as a science, a movement and a practice: a review. Agron. Sustain. Dev., v. 1, p. 1-13, 2009.

\section{Nota}

${ }^{1}$ D.L. Riquinho trabalhou na concepção do artigo, metodologia, pesquisa e escrita final. E.A. Hennington participou de todas as etapas do trabalho, orientando e revisando-o. 
Agricultural diversification in a rural locality in southern Brazil: reflections and alternatives in compliance with the Framework Convention on tobacco control

Agricultural diversification in tobacco growing areas is one of the proposals of the Framework Convention which is considered the first international public health treaty of the World Health Organization. The present study aimed to highlight and discuss the potentialities and weaknesses faced by State representatives, organizations of civil society and tobacco industries in the south of Brazil regarding agricultural diversification and the substitution of tobacco crops. An ethnographic type study with semistructured interviews was developed and conducted with 42 farming families and key informants, participant observation of families from a rural area of Rio Grande do Sul state, Brazil, was also applied. There are public policies which are capable to potentialize diversification such as agricultural credit and technical assistance. However, tobacco growers who were surveyed have not been reached yet. It is concluded that the rescue and strengthening of family agriculture are essential for agricultural diversification and substitution of tobacco cultivation as it is proposed by the Framework Convention.

Key words: rural health; tobacco; public health; sustainable agriculture; qualitative research. 